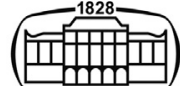

AKADÉMIAI KIADÓ

UNIVERSITY of DEBRECEN

\section{International Review of Applied Sciences and Engineering}

$12(2021) 2,127-133$

DOI:

$10.1556 / 1848.2020 .00189$

(c) 2020 The Author(s)

\section{ORIGINAL RESEARCH PAPER}

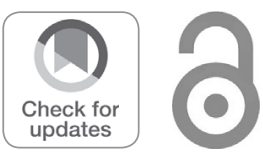

*orresponding author.

E-mail: mkalkat@ohu.edu.tr

\title{
Power and performance analysis of light bicycle on different road profiles
}

\author{
Menderes Kalkat* (우 \\ Mechanical Engineering Department, Engineering Faculty, Nigde Ömer Halisdemir University, \\ 51240, Nigde, Turkey
}

Received: October 6, 2020 • Accepted: November 18, 2020

Published online: March 25, 2021

\begin{abstract}
Nowadays, digital technology and measurement are improving to measure some systems in accurate conditions without errors. From these improvements and developments, it is necessary to analyse performances and condition of bicycle and biker before high level computations. In this experimental investigation, a high quality and very light bicycle and a well-equipped trained biker were trained to test the system with different road and region conditions. The purpose of this investigation is to predict unwanted conditions of bicycle before computations and activity. Otherwise, this kind of experimental trained testing will give some information from unwanted bicycle accidents. Moreover, in this experimental work, a power meter and measurement instrument with sensors are used to measure real time parameters. As can be concluded from experimental results and the analysis, the proposed work has a good design and analysis for good material bicycles. The displacement analysis is also outlined with load of a $63 \mathrm{~kg}$ biker.
\end{abstract}

\section{INTRODUCTION}

Advanced digital technology is developing very fast and there are many improvements for measurement of some parameters of systems in real time training and experimental works. Especially, advanced sensor technology has superior performance to measure many system's parameters in real time for modelling and analysing.

Nowadays, there are many investigations on experimental works. These investigations have been done by some researchers. However, some of the works have been researched by using simulations software and laboratory works on bikes. Abagnale and his research group have focused on investigating some environmental condition situation of the electric motor actuated bicycle with experimental biking in their research laboratory. In their work, they have tested a bicycle in close room conditions without any disturbances. They have tested and measured the system for overcoming unwanted aspects from the bicycle systems [1].

On the contrary, there are also other studies on the e-bike systems, apart from real time conditions. There were some experimental works related to electrical assisted bicycle by some researchers in [2-4]. They included a well developed bicycle for improving without any unwanted disturbances effect. Nowadays, e-bike systems are generally powered with rechargeable batteries [5-8]. They have investigated the actuating performance. These have been affected by using battery, motor power, road types, operation weight, control, and particularly the management.

On the other hand, a pure electric bicycle has been designed, analysed, and used for testing performance in [9-11]. This has been integrated driver such as electric motor into bicycle frame. However, other type of investigation included a power-assisted bicycle, and one called an e-bike in [12]. This system has been proposed as a kind of human-electric hybrid bicycle integration in [13], that was supporting the bicycle driver with electric power supply only when the driver was turning the pedals. 


\section{THEORY OF BICYCLES DURING}

\section{TRAVELLING}

Of all the components that can affect the character of a bike, wheels arguably have the best ability to make or break the way a bike rides. The best road bike wheels can all but transform your ride from sluggish and difficult to lively and exciting.

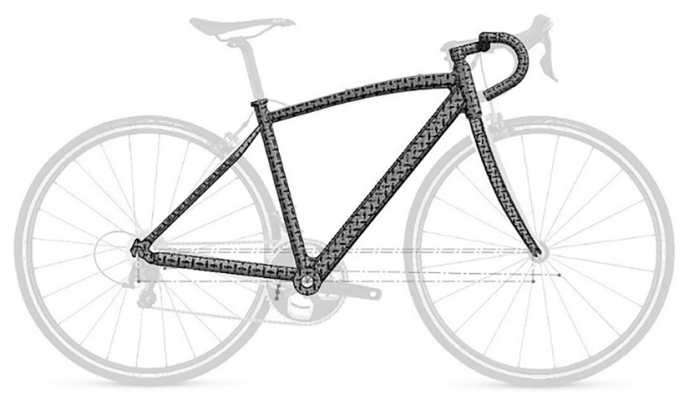

Fig. 1. A designed representation of the CAD model proposed bicycle
A light and stiff (but not too stiff) wheel will make your bike feel like it's gliding up a climb, help you effortlessly hold speed along the flats, and also improve steering accuracy. High-quality hubs keep things spinning along for years with a bit of elbow (or waterproof) grease here and there, and, most importantly, keeping the elements out [14].

There are many disturbances during travelling with different road profile for testing the bicycle with a professional biker. These unwanted disturbances can be outlined as the following: weather, temperature, roughness of road conditions, speed and position of wind such as air drag. The necessary equation of power $P_{D}$ is needed to overcome such disturbances, which can be indicated in the following equation:

$$
P_{D}=\frac{1}{2} \rho v_{a}^{3} C_{D} A
$$

where air density is denoted by $\rho$. The value of the air density is nearly $1.225 \mathrm{~kg} / \mathrm{m}^{3}$ at the sea level and $16 \mathrm{C}^{\circ}$, the speed relative of the air is denoted by $v_{a}$, and characteristic area is also denoted with drag coefficient $C_{D} A$.

$C_{D}$ is depended on the configuration of the object and the Reynolds number, this is depended on $v_{a}$. However, if cross

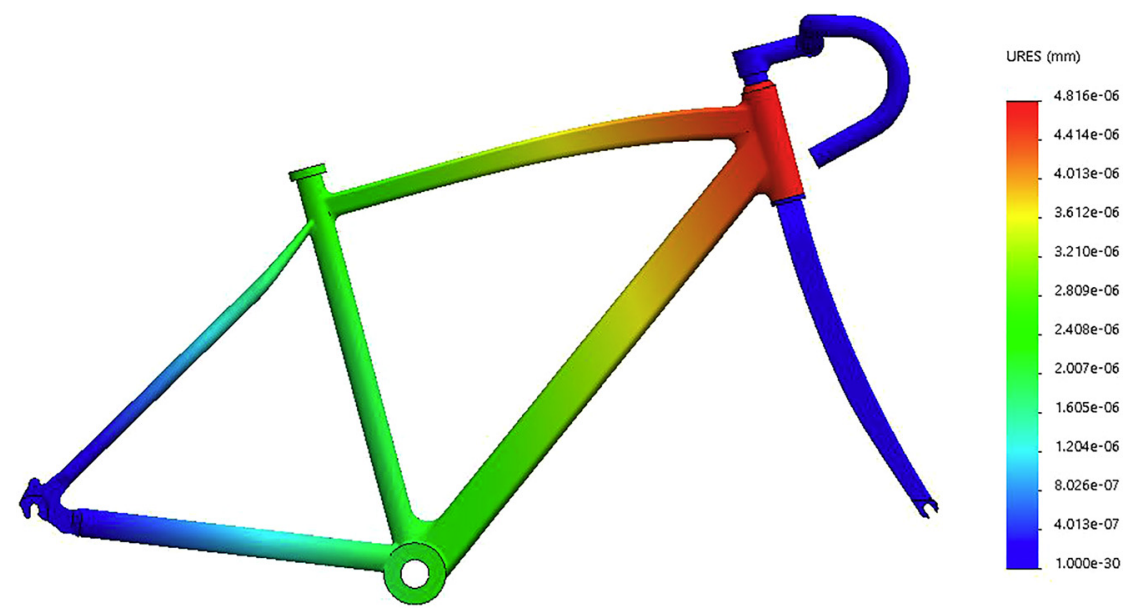

Fig. 2. Displacement analysis of the bicycle frame by using ANSYS

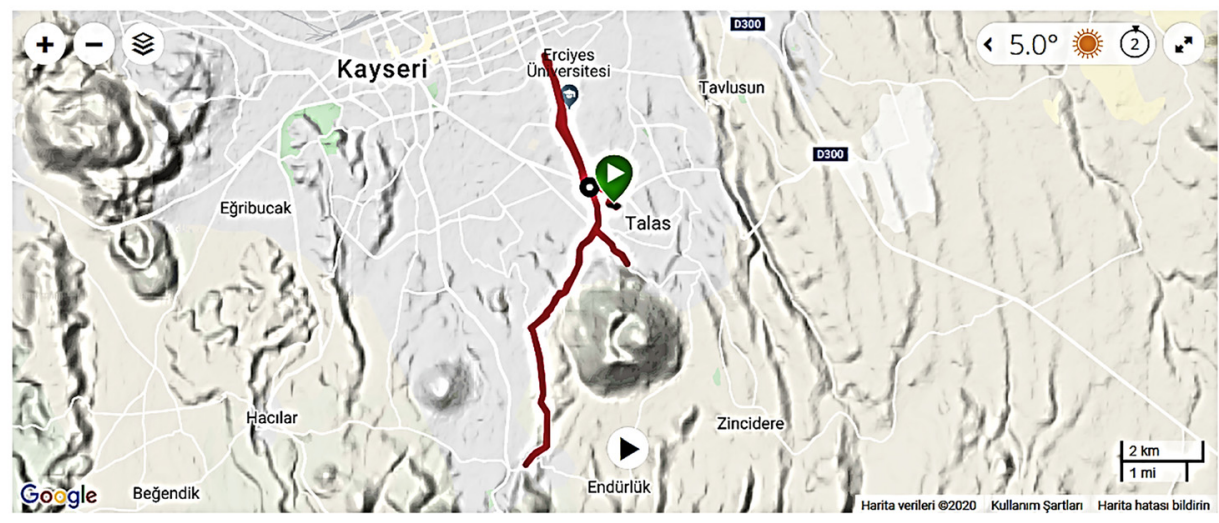

Fig. 3. Total trajectory view of the bicycle on the map 

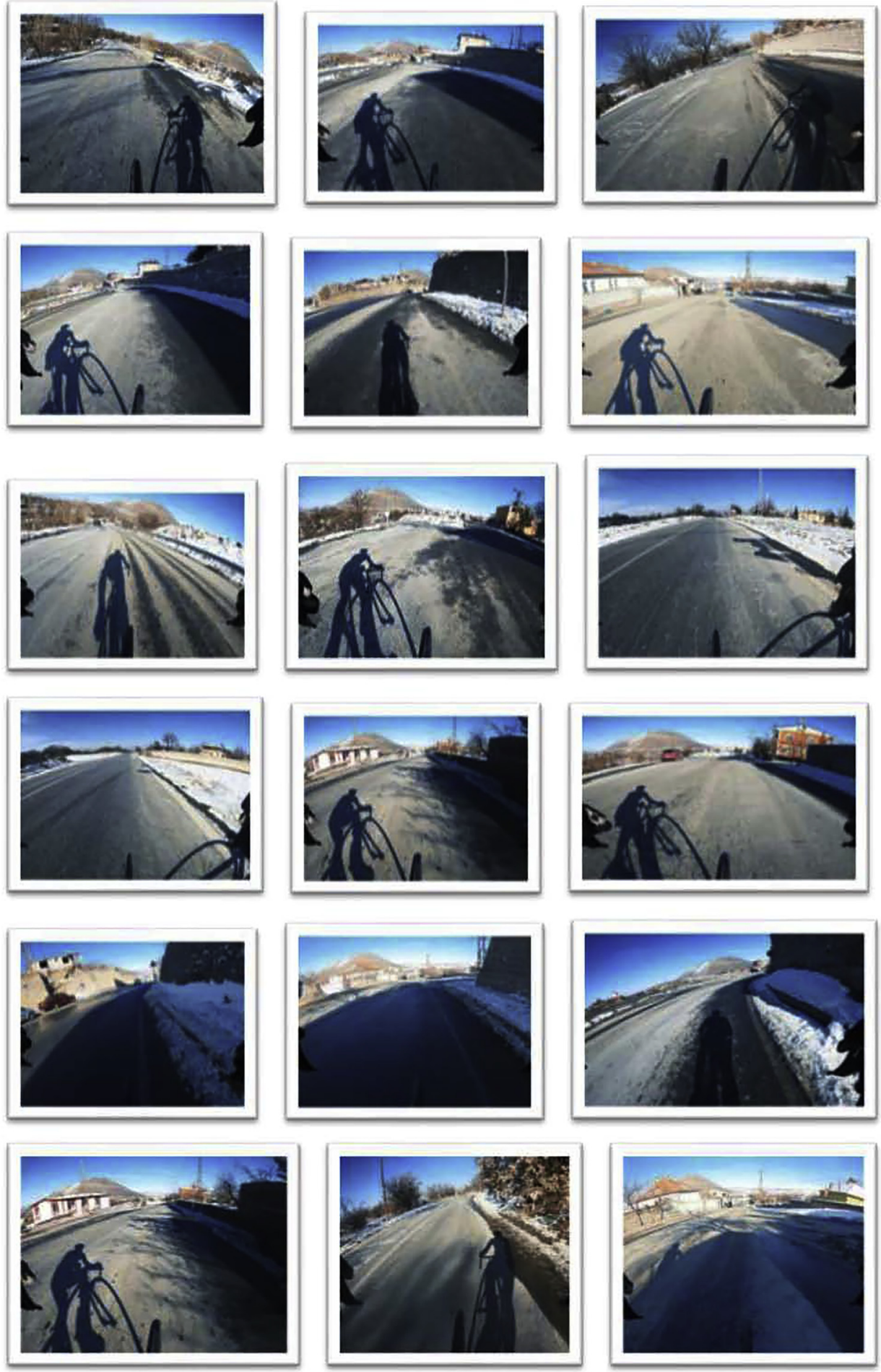

Fig. 4. Representing the road profile and roughness with photographs for each $1.5 \mathrm{~km}$ of $26.52 \mathrm{~km}$ distance

sectional area is denoted by $\mathrm{A}, C_{D}$ can be used number value of 1 for usual cycling speeds of a rider on an upright bicycle.

This power is produced to overcome the tires' rolling resistances. Furthermore, the applied power can be written in the following $\left(P_{R}\right)$

$$
P_{R}=v_{r} m g \cos (\arctan s) C_{r r} \approx v_{r} m g C_{r r}
$$

The gravity is denoted by $g$, the value of $g$ is almost $9,80,665$ $\mathrm{m} / \mathrm{s}^{2}$ and mass is denoted by $m$ in $(\mathrm{kg})$. The normal coefficients of rolling resistance are denoted by using $C_{r r}$. In general, $C_{r r}$ is assumed to be independent bicycle speed. The speed of bicycle during biking on the roads is denoted by $v_{r}$ [14].

The climbing power on vertical axes $P_{S}$ on a slope $s$ can be written in the following equation [15].

$$
P_{S}=v_{r} m g \sin (\arctan s) \approx v_{r} m g s
$$

The applied power on the bicycle is going to be increased with potential energy of a bicycle rider. Furthermore, there 
should be some problems such as falling down or braking troubles. There are other problems for a bicycle rider. However, the professional rider should be very careful about feeding himself with appropriate foods.

The accelerating power is denoted by using $P_{A}$. Furthermore, the bicycle and the rider having total mass $m$ with acceleration and rotationally also the wheels having mass denoted by $m_{w}$ is:

$$
P_{A} \approx v_{r}\left(m+m_{v}\right) a
$$

The total power can be outlined in the following expression;

$$
P=\left(P_{D}+P_{R}+P_{S}+P_{A}\right) / \eta
$$

where $\eta$ is the mechanical efficiency of the drive train.

\section{EXPERIMENTAL ANALYSIS RESULTS}

The model of the proposed experimental bicycle is shown in Fig. 1. As can be seen from the figure, the bicycle has been made of light material with $9.06 \mathrm{~kg}$ in total weight.

This section presents the proposed CAD model of trained and tested bicycle. Moreover, the displacement of bicycle frame is represented in Fig. 2 with $63 \mathrm{~kg}$ biker weight, the proposed by CAD model is exactly match to experimental bicycle system parameters. The material of bicycle frame is carbon-fiber.

The bicycle was tested along the distance of $26.52 \mathrm{~km}$ on icy and dry road with small roughness asphalt material (see Fig. 3). Green arrow shows the starting point of travel.

The training process was also photographed to show road conditions and profile completing the distance of 26.52 $\mathrm{km}$ for each $1.5 \mathrm{~km}$ (see Fig. 4). As can be seen from photographs, the road surface and profile are changing for each $1.5 \mathrm{~km}$.

As can be outlined in Fig. 5, starting elevation level was $1,159 \mathrm{~m}$ above sea level. The finishing elevation level was $1,160 \mathrm{~m}$. It seems that these points are on the same level, but there were very changeable road elevations. The maximum elevation was $1,470 \mathrm{~m}$ above sea level.

When the speed of the bicycle was analysed, initial speed was $26.9 \mathrm{kph}$ at $5 \mathrm{~s}$. The last speed of the bicycle was 19.5 $\mathrm{kph}$ at $24 \mathrm{~min}$ of travelling. Furthermore, maximum speed of bicycle was $70.2 \mathrm{kph}$ (see Fig. 6). These results proved that the speed was very reliable for computations.

The proposed bicycle was also analysed for cadence on the road of $26.52 \mathrm{~km}$ with roughness on icy and dry asphalt profile. However, the bike cadence was $76 \mathrm{rpm}$ at $5 \mathrm{~s}$ near the starting conditions (see Fig. 7). Nevertheless, the maximum bike cadence was $11 \mathrm{rpm}$ at $18 \mathrm{~min}$ of travelling.

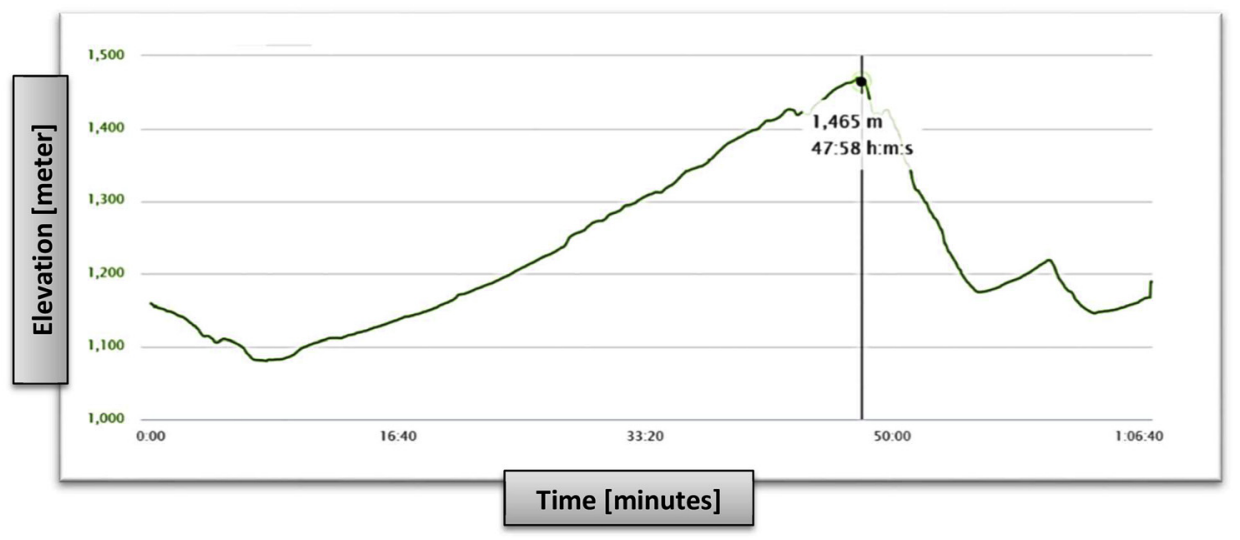

Fig. 5. Time - elevation variations during the travel of bicycle

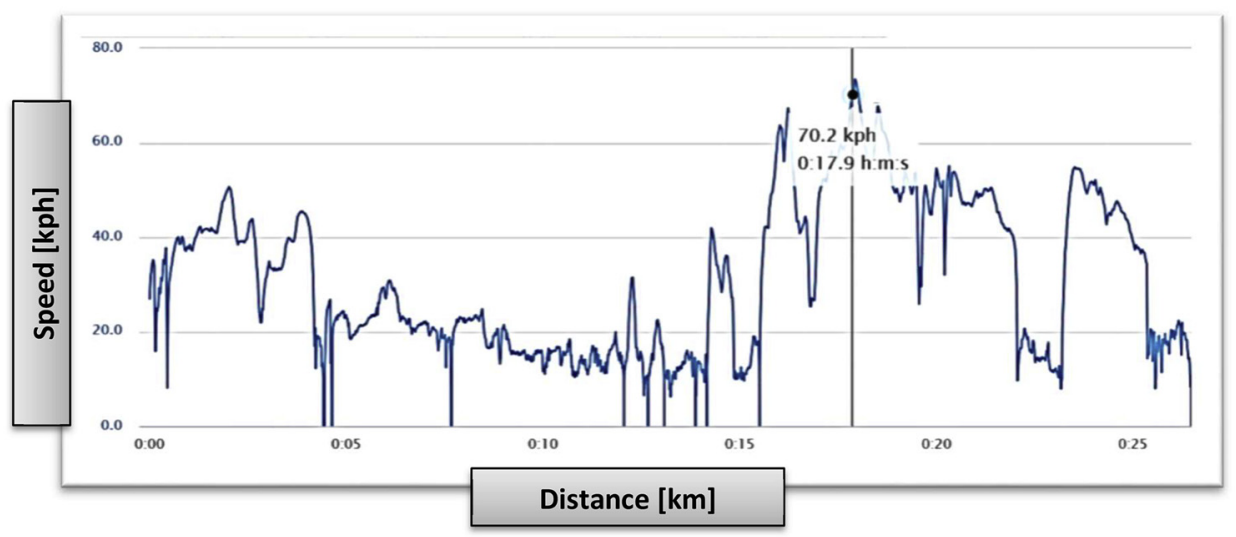

Fig. 6. Time-speed of bicycle variations 


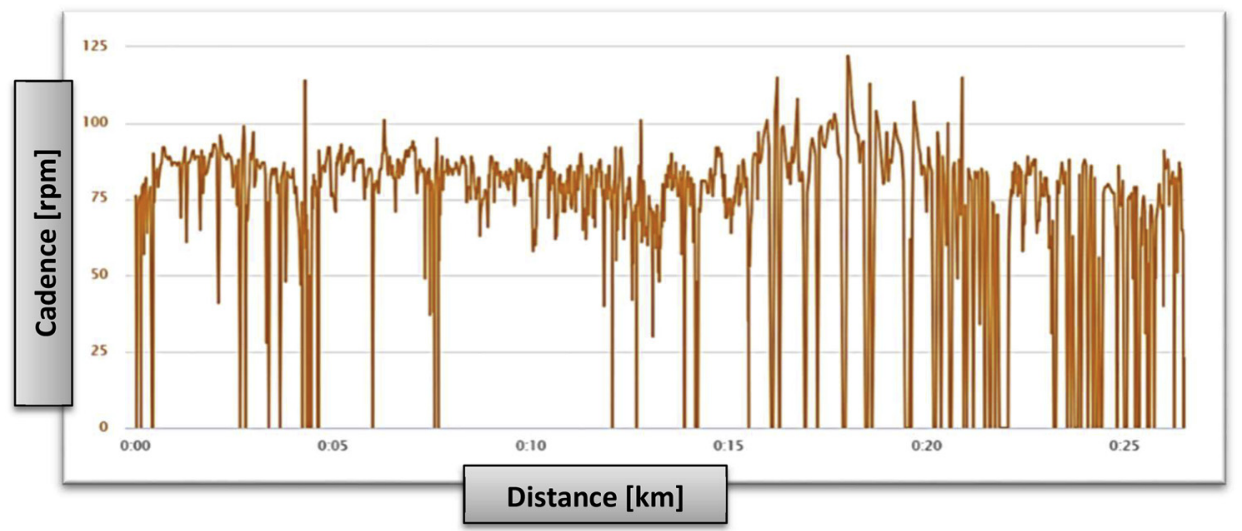

Fig. 7. Bike time-cadence variations during travelling of $26.52 \mathrm{~km}$

The results proved that the speed of bicycle was matching the road profile from the initial to final position.

The supplied power is very important to keep the calories constant. Furthermore, the supported power to drive bicycle by a biker should be very reliable for finishing the final point of computations. The measured initial power that is measured from the power meter was $24 \mathrm{~W}$ at $2 \mathrm{~s}$ of travelling. Furthermore, the maximum power was very high during travelling of $26.52 \mathrm{~km}$. As can be seen the results of power variations, the maximum power was $1,237 \mathrm{~W}$ at 20 min 9 s (see Fig. 8).

However, the weather conditions also affected the performance of a biker during a bicycle race. The systems were also analysed for weather temperature. Initially, the temperature was $25^{\circ} \mathrm{C}$ at the starting point, but the temperature suddenly changed from 25 to $5{ }^{\circ} \mathrm{C}$. For that reason, the

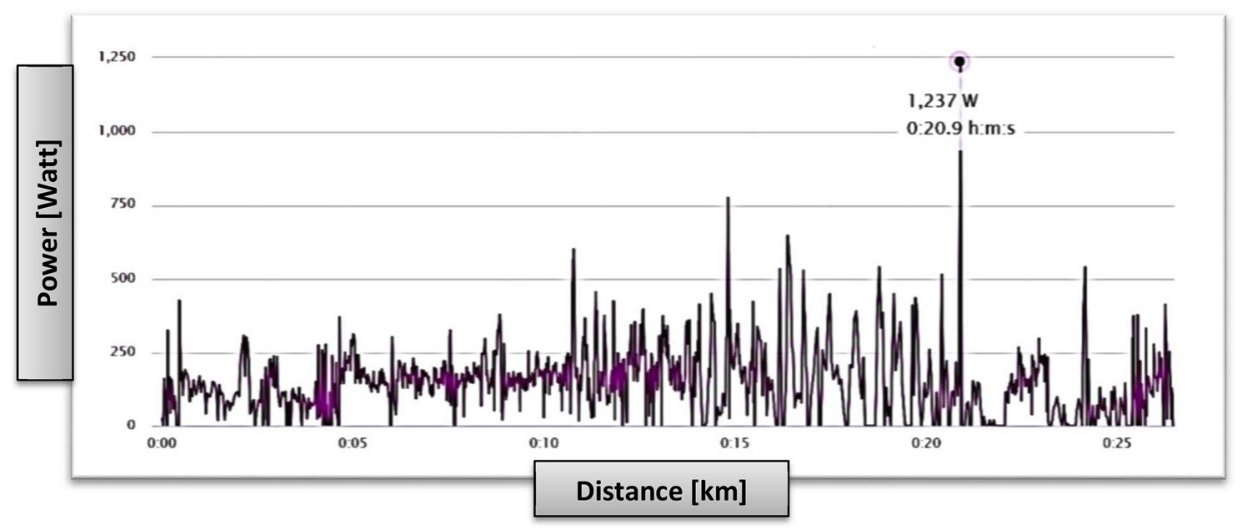

Fig. 8. The power-time variations during travelling of $26.52 \mathrm{~km}$

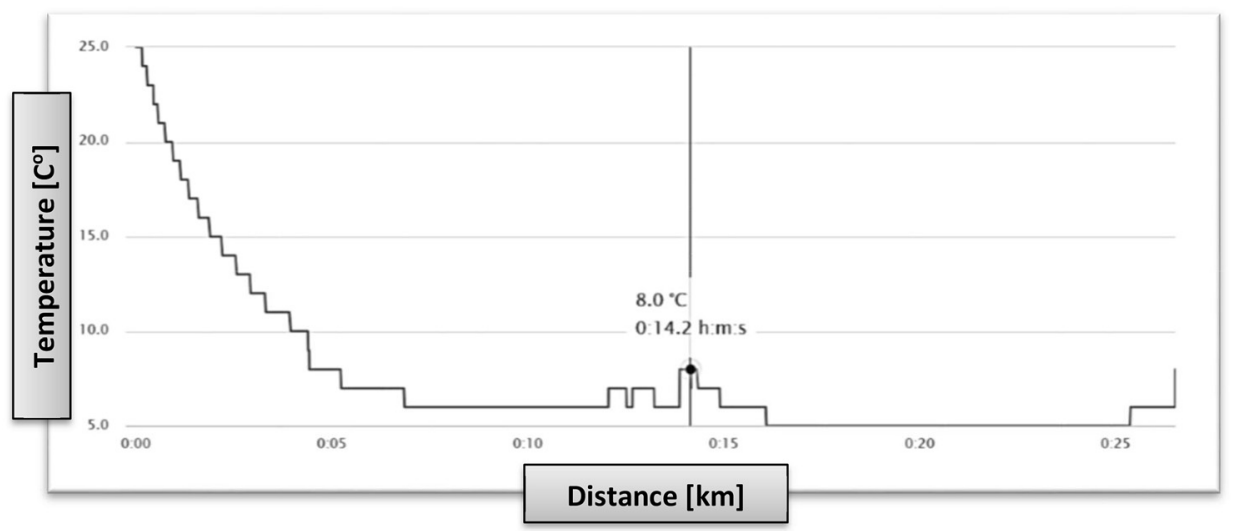

Fig. 9. Time-temperature variations during travelling all trajectory 


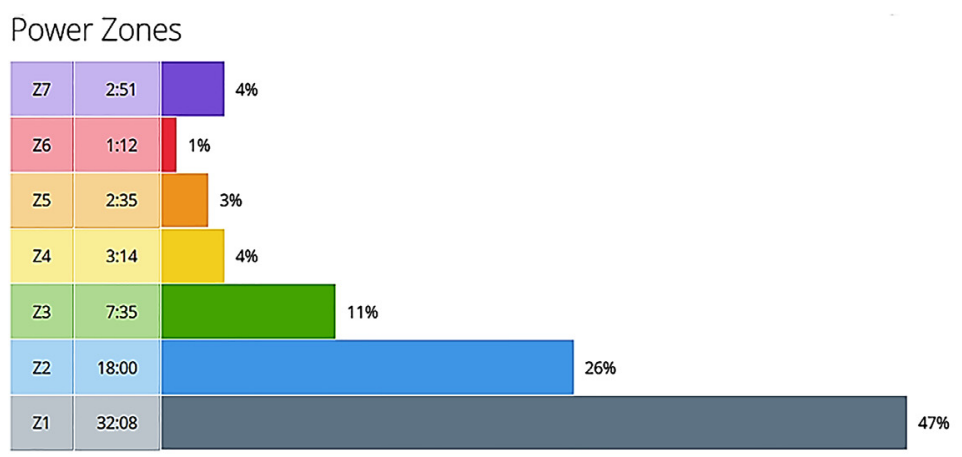

\section{Z7: ZONE 7-NEUROMUSCULAR, Z6: ZONE 6: ANAEROBIC, Z5: ZONE 5-VO2 MAX, Z4: ZONE 4-THRESHOLD, Z3: ZONE 3-TEMPO, Z2: ZONE 2-ENDURANCE, Z1: ZONE 1- ACTIVE RECOVERY}

Fig. 10. The times in zones of the bicycle and biker

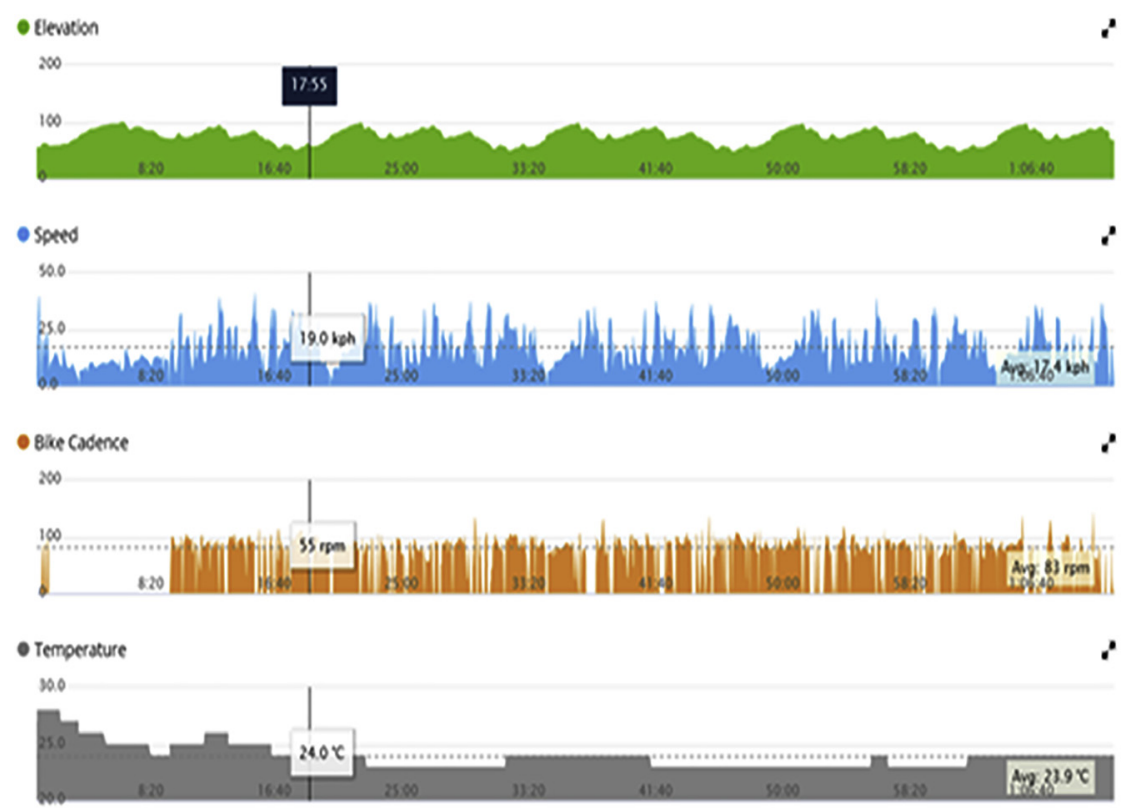

Fig. 11. Elevation, speed, bike cadence and temperature variations during travelling

performance of biker was slightly changed for the speed and cadence. Fig. 9 represents the temperature variations during travelling all trajectory of $26.52 \mathrm{~km}$.

The power zones of the bicycle and biker are indicated with 7 zones as shown in Fig. 10. It is easy to see from the figure that Zone 7 has very high percentage of 47 with active recovery. On the other hand, zone 6 anaerobic has very low percentage.

\section{CONCLUSIONS AND DISCUSSIONS}

This paper has presented an experimental investigation for analysing the performance of a race bicycle with a welltrained biker during travelling on different road conditions. In this, the performance and power conditions of the proposed bicycle have been analysed inn different aspects, such as cadence, elevation, temperature, speed, and road conditions with the length of $26.52 \mathrm{~km}$.

Full travelling time of the $26.52 \mathrm{~km}$ distance was 1 hour 7 min and $36 \mathrm{~s}$. Total moving time was $24 \mathrm{~s}$ less than full travelling time. Moreover, the elapsed time was also measured with 1:35:55. Average pace time for each $\mathrm{km}$ was $2: 33 \mathrm{~min} / \mathrm{km}$. There was also the best pace time, such as 0:49 $\mathrm{min} / \mathrm{km}$. Furthermore, the biker has lost nearly 660 calories along the whole travelling distance. Left and right torque effectiveness was 70\% L/0\% R. Left/Right Pedal Smoothness were $19 \% \mathrm{~L} / \mathbf{0} \% \mathrm{R}$. It is easy to see that due to road profile, the right side has $\mathbf{0} \%$. But the left side torque and pedal smoothness have some percentage.

On the other hand, some effects to the biker were measured during the completion of the distance of $26.52 \mathrm{~km}$. 
Moreover, intensity factor (IF) was 0.696 measured. Training Stress score was 54.2 measured from system. The total work was measured at $661 \mathrm{Kj}$. This work is reliable for this distance and road profile. Furthermore, the total strokes were measured as 4,914 because of road roughness and icy surface of asphalt road.

The main aim and purpose of this experimental work was to predict and analyse the cycling performance of a professional bicycle and a well exercised professional bike rider. As can be outlined and depicted from experimental results, the bicycle performance was adopted to icy and rough road profiles, weather conditions such as temperatures, cadences, elevations. Additionally, average power of $163 \mathrm{~W}$ is acceptable for this purpose.

Evaluation and comparison of power zones can be described as follows; zone 1 ( $\mathrm{Z1}$ ) active recovery has good performance (\%47) with the time of 32:08 $\mathrm{min}$. There is also good performance with the zone 2 (Z2) with the time period of 18:00 min has also acceptable performance of $\% 26$.

On the other hand, the time period decreased with the time of 1:12 min, the performance with power zone was $\% 1$.

Fig. 11 presents the Elevation, Speed, Bike Cadence and Temperature variations during travelling.

In future work, a neural network predictor analyser will be employed to predict such parameters in real time applications for the exact analysis of this kind of systems. However, the proposed system can be employed on different road conditions, such as dry without asphalt.

\section{REFERENCES}

[1] C. Abagnale, M. Cardone, P. Iodice, S. Strano, M. Terzo, and G. Vorraro, "A dynamic model for the performance and environmental analysis of an innovative e-bike," Energy Proced., vol. 81, pp. 618-27, 2015.

[2] H. Seki, K. Ishihara, and S. Tadakuma, "Novel regenerative braking control of electric power-assisted wheelchair for safety downhill road driving," IEEE Trans. Ind. Electron., vol. 56, no. 5, pp. 1393-400, May 2009.
[3] C. C. Tsai, H. C. Huang, and S. C. Lin, "Adaptive neural network control of a self-balancing two-wheeled scooter," IEEE Trans. Ind. Electron., vol. 57, no. 4, pp. 1420-8, Apr. 2010.

[4] A. Emadi, Y. J. Lee, and K. Rajashekara, "Power electronics and motor drives in electric, hybrid electric, and plug-in hybrid electric vehicles," IEEE Trans. Ind. Electron., vol. 55, no. 6, pp. 2237-45, Jun. 2008.

[5] A. Muetze and Y. C. Tan, "Electric bicycles: A performance evaluation," IEEE Ind. Appl. Mag., vol. 13, no. 4, pp. 12-21, Jul./ Aug. 2007.

[6] Y. Tanaka, and T. Murakami, "A study on straight-line tracking and posture control in electric bicycle," IEEE Trans. Ind. Electron., vol. 56, no. 1, pp. 159-68, Jan. 2009.

[7] M. Defoort, and T. Murakami, "Sliding-mode control scheme for an intelligent bicycle,” IEEE Trans. Ind. Electron., vol. 56, no. 9, pp. 3357-68, Sep. 2009.

[8] E. A. Lomonova, A. J. A. Vandenput, J. Rubacek, B. d'Herripon, and G. Roovers, "Development of an improved electrically assisted bicycle," in Conf. Rec. IEEE IAS Annu. Meeting, vol. 1, 2002, pp. 384-9.

[9] P. Fairley, "China's cyclists take charge: Electric bicycles are selling by the millions despite efforts to ban them," IEEE Spectr., vol. 42, no. 6, pp. 54-9, Jun. 2005.

[10] N. Somchaiwong and W. Ponglangka, "Regenerative power control for electric bicycle," in Proc. IEEE Int. Joint Conf. SICE-ICASE, pp. 4362-5, 2006.

[11] M. J. Yang, H. L. Jhou, B. Y. Ma, and K. K. Shyu, "A cost-effective method of electric brake with energy regeneration for electric vehicles," IEEE Trans. Ind. Electron., vol. 56, no. 6, pp. 2203-12, Jun. 2009.

[12] D. Schneider, "Easy rider: Convert your bicycle to a human-electric hybrid," IEEE Spectr., vol. 46, no. 9, pp. 26-7, Sep. 2009.

[13] W. Du, D. Zhang, and X. Zhao, "Research on battery to ride comfort of electric bicycle based on multi-body dynamics theory," in Proc. IEEE Int. Conf. Autom. Logistics, Aug. 2009, pp. 1722-6.

[14] J. C. Martin, D. L. Milliken, J. E. Cobb, et al., "Validation of a mathematical model for road cycling power," J. Appl. Biomech., vol. 14 , no. 3, pp. 276-91, 1998.

[15] https://www.cyclingnews.com/features/best-road-bike-wheels/. 